\title{
Review
}

\section{Role of Janus Kinase Inhibitors in Therapy of Psoriasis}

\author{
Sylwia Słuczanowska-Głąbowska, Anna Ziegler-Krawczyk, Kamila Szumilas (1) and Andrzej Pawlik*(D)
}

check for

updates

Citation: Słuczanowska-Głąbowska,

S.; Ziegler-Krawczyk, A.; Szumilas,

K.; Pawlik, A. Role of Janus Kinase

Inhibitors in Therapy of Psoriasis. J.

Clin. Med. 2021, 10, 4307. https://

doi.org/10.3390/jcm10194307

Academic Editor: Mayumi Komine

Received: 30 August 2021

Accepted: 16 September 2021

Published: 22 September 2021

Publisher's Note: MDPI stays neutral with regard to jurisdictional claims in published maps and institutional affiliations.

Copyright: (c) 2021 by the authors. Licensee MDPI, Basel, Switzerland. This article is an open access article distributed under the terms and conditions of the Creative Commons Attribution (CC BY) license (https:// creativecommons.org/licenses/by/ $4.0 /)$.
Department of Physiology, Pomeranian Medical University in Szczecin, 70-111 Szczecin, Poland; sylwia@pum.edu.pl (S.S.-G.); ania.ziegler@op.pl (A.Z.-K.); kamila.szumilas@pum.edu.pl (K.S.)

* Correspondence: pawand@poczta.onet.pl

\begin{abstract}
Janus kinases inhibitors are molecules that target Janus kinases—signal transducers and activators of transcription (JAK/STAT). They inhibit this intracellular signal pathway, blocking the gene transcription of crucial proinflammatory cytokines that play a central role in the pathogenesis of many inflammatory and autoimmune diseases, including psoriasis. This process reduces psoriatic inflammation. The JAK inhibitors are divided into two generations. The first generation of JAK inhibitors blocks two or more different Janus kinases. The second generation is more specified and blocks only one type of Janus kinase and has less side effects than the first generation. Tofacitinib, ruxolitinib and baricitinib belong to first generation JAK inhibitors and decernotinib and filgotinib belong to second group. This narrative review summarizes the role of Janus kinase inhibitors in the therapy of psoriasis. Oral JAK inhibitors show promise for efficacy and safety in the treatment of psoriasis. Studies to date do not indicate that JAK inhibitors are superior to recent biologic drugs in terms of efficacy. However, JAK inhibitors, due to their lack of increased incidence of side effects compared to other biologic drugs, can be included in the psoriasis treatment algorithm because they are orally taken. Nevertheless, further studies are needed to evaluate long-term treatment effects with these drugs.
\end{abstract}

Keywords: psoriasis; Janus kinases; therapy

\section{Introduction}

Psoriasis vulgaris is a common inflammatory, chronic skin disease that affects $2 \%$ to $3 \%$ of the world population. It is a disease with periods of exacerbation and remission. Psoriasis vulgaris has a genetic basis and multigenetic inheritance. Many factors play a role in the development of psoriasis, among which are distinguished: environmental and immunological factors. However, the influence of genetic conditions and multigene background is underlined.

There are two types of psoriasis. Type I is associated with autosomal dominant inheritance, occurring in up to 40 years of age and is associated with HLA-Cw6 tissue compatibility antigens, as well as B13 and B57. Type II appears for the first time between 50 and 70 years of age and is associated with HLA antigens Cw6, Cw2 and B27. Thus far, no specific gene responsible for psoriasis has been found, and HLA-Cw6 alleles are also found in the normal population [1-3].

The most common variant of this disease, affecting $85-90 \%$ of patients, is plaque psoriasis. In addition, there is palmoplantar psoriasis, erythrodermic psoriasis, and inverse psoriasis as well as generalized pustular psoriasis, which is alternatively termed von Zumbush type. In addition to isolated skin lesions, 25\% of patients with psoriasis and joint lesions are diagnosed with psoriatic arthritis [1].

The skin lesions of psoriasis are erythematous scaly plaques, which are preferentially disposed at extensor sites and in areas of mechanic stress such as the knees and elbows. They are characterized by hyperplasia and parakeratosis with accumulation of inflammatory cells in the dermis. In addition, scalp, nails and inverse regions can also be affected [4]. 
The inflammatory response in psoriasis is mainly driven by $\mathrm{T}$ cells, especially $\mathrm{T}$ helper cells (Th17), and is mediated by different cytokines, especially TNF- $\alpha$, IL-17, IL-23 but also other cytokines such as IFN- $\gamma$, IL-2, IL-6, IL-8, IL-17, IL-18 and IL-22. The IL-23 is crucial in the pathogenesis of psoriasis and causes Th17 cells to produce IL-17 and IL-22. They induce changes in the skin characteristic for psoriasis. Psoriasis severity is generally characterized by the Psoriasis Area and Severity Index (PASI), which is usually presented as a percentage response rate $[2,4,5]$.

There is a wide range of treatment possibilities for psoriasis. The treatments include mainly topical medicines such as ointments with urea, salicylic acid and cygnoline, glucocorticosteroids and vitamin D derivatives and phototherapy. In moderate to severe cases of psoriasis, oral drugs such as acitretin and immunosuppressive drugs such as methotrexate and cyclosporine were given. In recent years, new groups of medicine were used in the treatment of psoriasis, which are biologics. The biologic drugs targeting TNF, IL-12/IL-23, and IL-17 have been approved for the treatment of psoriasis in the last few years, but not all patients respond to treatment with biologics. The biologics are efficient, well tolerated, and safe for treatment of psoriasis but are expensive [4,6-8]. The Janus kinase (JAK) inhibitors are a new class of drugs that can be used in systemic treatment of psoriasis, and they are less expensive.

\subsection{Janus Kinases}

Janus kinase (JAK) is the non-receptor tyrosine kinase that transduces signals from multitudes of cytokines and growth factors and plays a major role in the pathogenesis of many inflammatory and autoimmune diseases, including psoriasis [4,9]. The JAKs are intracellular enzymes that bind to the cytoplasmic domains of cytokine receptors [10,11]. In recent years, there have been many trials about modulating the key intracellular components of cytokine signaling through Janus kinases (JAK) $[2,4,12]$.

Cytokines are a group of proteins consisting of different structures. They act on different signal transductions, as a result of joining receptors, and they are grouped depending on the receptor to which they join. The binding of cytokines to their receptors initiates an inflammatory signal that can be mediated by JAK. The large group of cytokines such as IL-2, IL-4, IL-6, IL-7, IL-9, IL-12, IL-15, IL-21, IL-22 and IL23 as well as interferons such as INF-gamma bind to type I and II cytokine receptors $[13,14]$.

When cytokines bind to receptors, the intracellular JAKs are recruited and joined in pairs to the intracellular part of the cytokine receptors, and then, they are activated. The dimerization of JAKs formats heterodimers, autophosphorylate, and attracts STAT (signal transducer and activator of transcription) protein. Afterward, the activated STAT proteins dimerize and translocate to the cell nucleus, where they regulate gene transcription of different cytokines, including proinflammatory cytokines that play role in pathogenesis of psoriasis [6,14-17] (Figure 1).

JAK was discovered in the end of the last century [18]. In mammals, there are four JAK proteins: JAK1, JAK2, JAK3, and TYK2 (tyrosine kinase 2) [11] and seven STATs [4,11]. JAK1, JAK2, and TYK2 are involved in cell growth processes in different cell types, they partake in their development and differentiation, while JAK3 is critical to hematopoiesis $[14,15,19,20]$. JAKs are crucial for intracellular signaling of lymphocytes. Their dysfunction is involved with impairment of immune cells $[15,21]$. The JAK/STAT signaling pathway is typically found in many inflammatory skin diseases including psoriasis $[10,13]$. It was shown that JAK1 expression correlates with duration of psoriasis and Psoriasis Area and Severity Index (PASI) score [7].

Different JAKs are associated with specific cytokine receptors and influence different aspects of immune cell development and function. JAK1 is associated with INF, IL-6 and Il-10 receptors and with receptors containing the common gamma chain during JAK2 with hematopoetic receptors as well as the IL-12 and IL-23 receptors. JAK3 is associated with major cytokines for lymphocyte function IL-2, IL-4, IL-7, IL-9, IL-15 and IL-21 receptors. The TYK2 is conjuncted with JAK2 and associated with INF, IL-12 and IL-23 receptors [17,21,22]. 
Mutations of JAK cause dysfunction of cells and diseases such as essential thrombocytopenia, myelofibrosis, polycythemia vera, severe combined immunodeficiency, autoimmune diseases and others $[14,16,20,23]$.

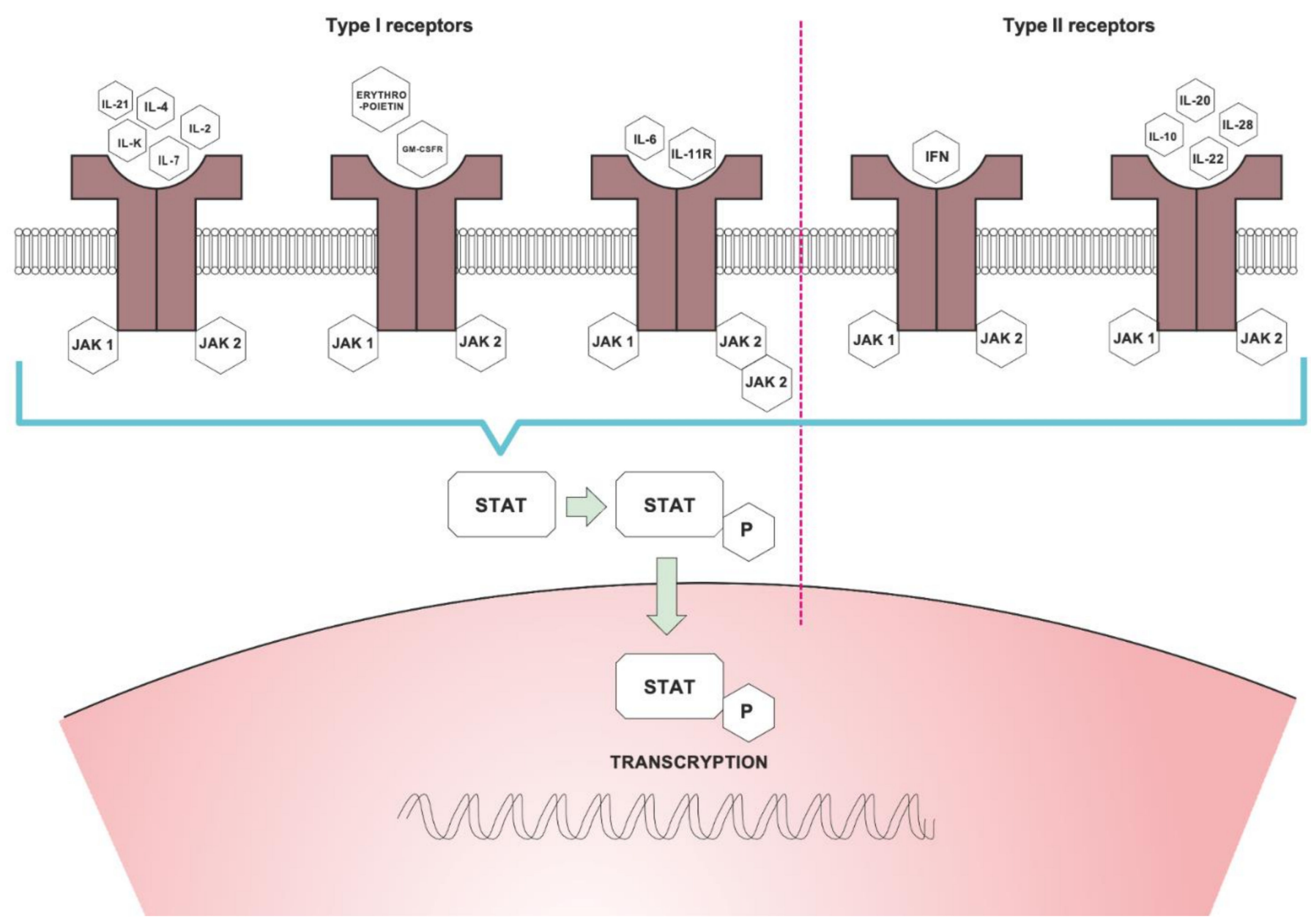

Figure 1. Mechanisms of action of Janus kinases. JAK—Janus kinase, STAT—signal transducer and activator of transcription; P-phosphoric acid, GM-CSF-Granulocyte-macrophage colony-stimulating factor, IFN-Interferon.

\subsection{Janus Kinase Inhibitors}

JAK inhibitors improve the treatment of many inflammatory diseases, including psoriasis [18]. JAK inhibitors are the molecules targeting the Janus kinase-a signal transducer and activator of transcription (JAK/STAT). They block this intracellular signal pathway by blocking the gene transcription of crucial proinflammatory cytokines, which play a central role in the pathogenesis of many inflammatory and autoimmune diseases including psoriasis $[9,10]$ (Figure 2). This process reduces psoriatic inflammation $[14,16,23]$. JAK inhibitors target JAKs inside the cell [14,24]. The JAK inhibitors are divided into two generations. The first generation of JAK inhibitors target two or more different JAKs. The second generation is more specified and target only one type of JAK and has less side effects than the first generation $[14,25]$. Tofacitinib, ruxolitinib and baricitinib belong to first generation of JAK inhibitors and the decernotinib and filgotinib to the second group $[13,14,25]$.

\subsection{JAK Inhibitors in Psoriasis Treatment}

Knowledge about biologics used for psoriasis (such as ustekinumab, secukinumab, ixekizumab, risankizumab) targeting the IL23/IL17 axis, shows that there is also therapeutical potential of JAK inhibitors associated with receptors for these cytokines. The blocking by JAK inhibitors of cytokines pathway may suppress the expression of many 
cytokines important for pathogenesis of psoriasis $[4,14,25,26]$. For example, IL-23, the crucial interleukin in the pathogenesis of psoriasis, transduces the signal by JAK2 and TYK2 [14,27] and can be a target for the treatment of psoriasis [4].

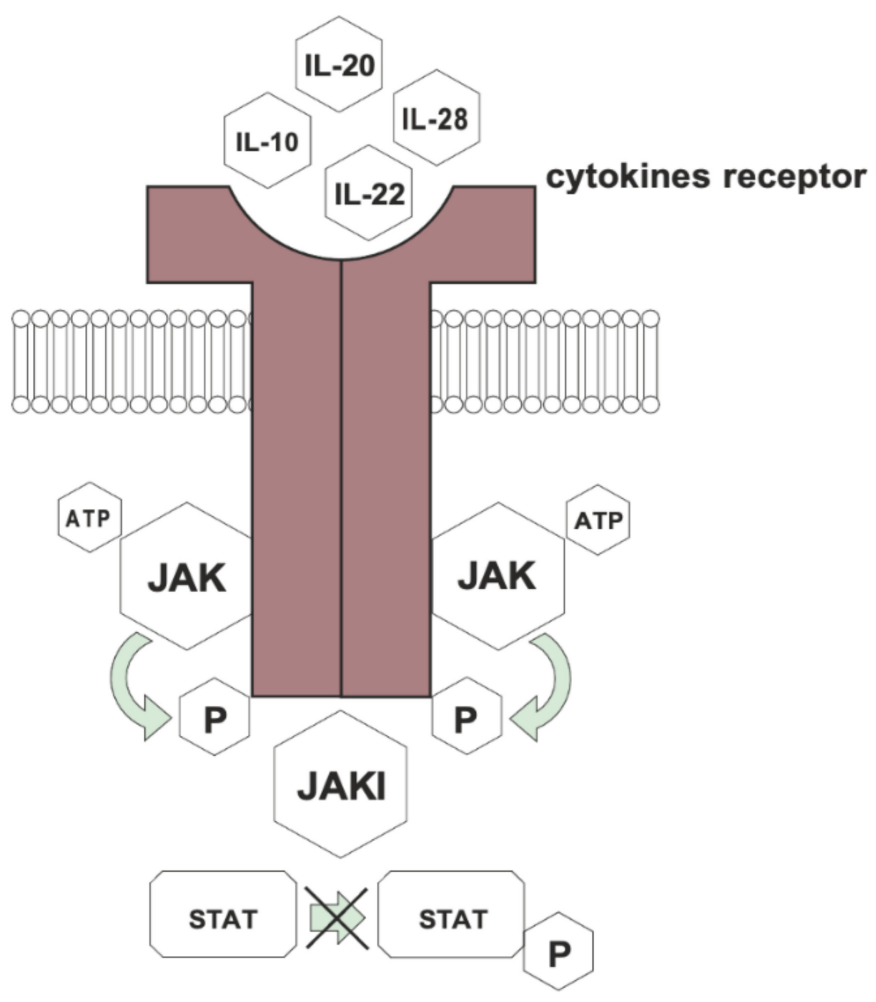

The JAKI bindina ATPsite at JAK

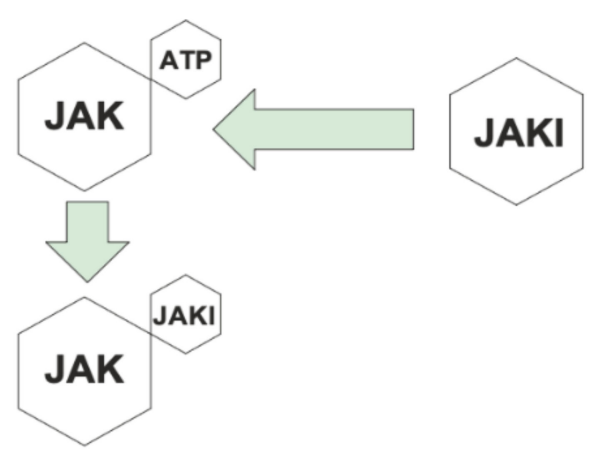

Figure 2. Mechanisms of action of Janus kinase inhibitors. JAK—Janus kinase, JAKI—Janus kinase inhibitor, STAT—-signal transducer and activator of transcription; $\mathrm{P}$ - phosphoric acid, ATP-Adenosine triphosphate.

The JAK inhibitors are currently under clinical investigation for oral and topical treatment in psoriasis $[4,10,13,28]$. Currently, the three JAK inhibitors, tofacitinib, baricitinib, and ruxolitinib, have been approved for clinical use in psoriasis in the United States of America and Europe [4,29].

\subsection{Tofacitinib-General Information and Clinical Trials}

Tofacitinib is the most studied JAK inhibitor in cutaneous diseases. It is now being explored in skin diseases and do not respond to or sustain intolerable adverse effects as an immunosuppressive and biologic treatment $[10,11]$. Compared to immunosuppressives and biologics treatment, tofacitinib is easy to administer and can be used orally or topically [11]. Besides being used in psoriasis [4,29], tofacitinib is being used as an off-label indication in alopecia areata, vitiligo and atopic dermatitis $[11,15,30]$. It is also used in treatment in skin diseases such as moderate to severe active rheumatoid arthritis [15,31-34], psoriatic arthritis $[15,32,35]$, and ulcerative colitis $[15,36]$.

Tofacitinib, a first-generation JAK inhibitor, blocks tyrosine kinases of the Janus family such as JAK1 and JAK3, with affinity for JAK2 and TYK 2 [10,15,37]. Tofacitinib is rapidly eliminated. The peak level of tofacitinib occurs within $30 \mathrm{~min}$, and the half-life is $3 \mathrm{~h}$. It is metabolized mainly by the liver, primarily mediated by CYP3A4 with minor contribution from CYP2C19, and metabolized at a low percentage in kidneys. It is excreted renally $[11,31,38-40]$. In pregnancy, is not well established and can be used only if benefits outweigh the potential risks. There is a reported small amount of cases of pregnant women who received tofacitinib [11,41]. Tofacitinib is secreted in breast milk and breastfeeding is avoided during treatment [11]. In the pediatric population, studies are not robust. This drug cannot be used in those less than 18 years of age [11]. 
Tofacitinib is the most studied JAK inhibitor used to heal chronic plaque psoriasis orally $[14,19,23]$. It was shown that treatment with tofacitinib (10 mg twice daily) decreases epidermal thickness, reduces of the number of T cells infiltrating the skin, and suppresses the IL-23/Th17 pathway [11].

The action of this drug is decreased during concurrent administration of the potent CYP3A4 inducers (e.g., Rifampicin) and is increased during concurrent administration of potent inhibitors of CYP3A4 (e.g., ketoconazole and flukonazole). The immunosuppressive drugs, e.g., azathioprine, tacrolimus, and cyclosporine, are avoided during treatment with tofacitinib because of increased risk of immunosuppression. In addition, disease-modifying anti-rheumatic drugs and biologics are not well studied and are not recommended for coadministration because of an increased risk of immunosuppression [11]. The therapy with tofacitinib should not be started in the following conditions: active infection, hematological abnormalities, severe hepatic impartment, and hypersensitivity to the active substance or to any excipients [11].

The effectiveness of oral administration of tofacitinib was confirmed in the treatment of moderate to severe plaque psoriasis phase III trials [42,43]. The effectiveness and safety of tofacitinib (in dose 5 and $10 \mathrm{mg}$ twice daily) was described in two phase III trials in patients with active psoriasis arthritis. In these trials, tofacinitib was used in combination with methotrexate, sulfasalazine and leflunomide [33,34,44].

Tofacitinib was also be used as a topical treatment. The topical application of $2 \%$ tofacitinib ointment decreased possible systemic adverse effects. It was tested in a phase II trial. It was observed to have a better effect than placebo [24,45].

\subsubsection{PIVOTAL 1 and PIVOTAL 2-Phase III Studies of Tofacitinib Treatment}

The most important studies of tofacitinib were Pivotal 1 and 2 . The duration of these trials was 52 weeks. These were phase III double-blinded studies, which compared tofacitinib $5 \mathrm{mg}$ twice daily and $10 \mathrm{mg}$ twice daily with placebo. The Pivotal 1 study was conducted in 74 centers and the Pivotal 2 study in 94 centers, both in the USA, Canada, Colombia, Germany, Hungary, Japan (Pivotal 1 only), Mexico, Poland, Puerto Rico (Pivotal 2 only), Serbia, Taiwan and Ukraine. Inclusion criteria was age over 18 years, diagnosis of plaque-type psoriasis for over 12 months before the first dose of tofacitinib, Psoriasis Area and Severity Index (PASI) score over 12, psoriatic lesion involvement greater than 10\% body surface area (BSA) and Physician's Global Assessment (PGA) score of 3 (moderate) or 4 (severe). PGA is a five-point scale that shows global consideration of erythema, induration, and scaling of psoriatic lesions. Patients had to be candidates for systemic therapy or phototherapy independently of use of prior systemic agents. Exclusion criteria: nonplaque psoriasis systemic, infections, evidence of active, latent or improperly treated Mycobacterium tuberculosis infection, present drug-induced psoriasis, malignancy or history of malignancies, and receiving of efalizumab previously [46]. Patients were recruited by the investigators and were randomized 2:2:1 to administer tofacitinib: $5 \mathrm{mg}-$ 745 patients, $10 \mathrm{mg}-741$ patients or placebo-373 patients, twice daily.

End points consisted of the proportion of patients achieving PASI 90 at week 16, the percentage change from baseline in BSA at week 16, change from baseline Dermatology Life Quality Index (DLQI) total score at week 16, the proportion of patients achieving PGA response at week 4, change from baseline DLQI total score at week 4, the proportion of patients achieving PASI 75 at week 4, and percentage change from baseline Nail Psoriasis Severity Index (NAPSI) at week 16 in patients with nail psoriasis at baseline. Another secondary efficacy end point included time to PASI 75 or PGA response to week 16. Patients who received placebo were randomized at week 16 to be given tofacitinib 5 or $10 \mathrm{mg}$ twice daily-it continued until week 52. Patients who did not achieve PASI 75 or PGA score of "clear" or "almost clear" at week 28 were drawn back [42,43].

In this study, it was observed during Pivotal 1 and Pivotal 2, with similar protocols, that the efficacy of oral tofacitinib, with the $10 \mathrm{mg}$ twice daily, was more efficacious than the $5 \mathrm{mg}$ daily. The psoriasis patients who received tofacitinib in 5 or $10 \mathrm{mg}$ twice daily 
achieved PASI75 at week 16 in higher percentages (OPT Pivotal 1, 5 mg: 39.9\%; $10 \mathrm{mg}$ : 59.2\% and OPT Pivotal 2, $5 \mathrm{mg}: 46.0 \%$; $10 \mathrm{mg}: 59.6 \%$ ), compared with those receiving placebo (OPT PIVOTAL 1: 6.2\%; OPT PIVOTAL 2: 11.4\%). The proportions of patients achieving PGA responses at week 16 with tofacitinib 5 and $10 \mathrm{mg}$ twice daily were in OPT Pivotal 1: $41.9 \%$ and $59.2 \%$ versus placebo $9.0 \%$, and in OPT PIVOTAL 2: $46.0 \%$ and $59.1 \%$ versus placebo $10.9 \%$. These results were maintained until month 24 . Discontinuation of treatment by tofacitinib was associated with a risk of return of lesions, but restart of the treatment rapidly decreased psoriatic inflammation. Retreatment recovery efficacy existed in $\sim 60 \%$ of the patients. The reason for this is unknown $[4,7,10,42,43,47-52]$. In conclusion, tofacitinib 5 and $10 \mathrm{mg}$ twice daily showed clinically relevant efficacy versus placebo over a 16-week period [42,43].

\subsubsection{OPT Compare-Phase III Studies of Tofacitinib Treatment}

Another phase III trial was OPT Compare. It was conducted to compare tofacitinib $5 \mathrm{mg}$ twice daily or $10 \mathrm{mg}$ twice daily with etanercept $50 \mathrm{mg}$ twice weekly and placebo. It was a randomized multicenter study that proved that the efficacy of tofacitinib $10 \mathrm{mg}$ twice daily is non-inferior at week 12 to the efficacy of etanercept $50 \mathrm{mg}$ twice weekly in psoriasis. The primary end point was evaluated at week 12 . Only adult patients with chronic stable plaque psoriasis (for $\geq 12$ months) participated in this trial. The patients were recruited from 122 investigational dermatology centuries from different countries. They were candidates for phototherapy or systemic treatment. The inclusion criteria were a Psoriasis Area and Severity Index (PASI) score $\geq 12$, a Physician's Global Assessment (PGA) of moderate or severe, and no response to at least one conventional systemic therapy or a contraindication or intolerance to this therapy $[7,13]$.

Between November 2010 and September 2012, 1106 patients were grouped in a proportion of 3:3:3:1. In the first group, the patients received $5 \mathrm{mg}$ of tofacitinib twice per day, in the second $-10 \mathrm{mg}$ twice daily, in the third $-50 \mathrm{mg}$ of etanercept twice a week and in the last group - placebo. In this trial, PASI75 was achieved at week 12 by $39.5 \%$ patients of the first group, $63.6 \%$ of the second group, $58.8 \%$ of the third group and $5.6 \%$ of the group with placebo. The PGA was better in $47.1 \%$ of patients in the first group, in $68.2 \%$ in the second, in $66.3 \%$ in the third group and in $15.0 \%$ in the placebo group. All active groups achieved a Dermatology Life Quality Index score of 0 or 1 in significantly higher percentages compared with placebo $(p<0.0001$, for all comparisons). The $10 \mathrm{mg}$ tofacitinib-treated group achieved an Itch Severity Item score of 0 or 1 in a greater percentage of patients compared with etanercept, from week 2 up until week 12 ( $p<0.05$ for all comparisons) $[14,20,44,53]$. Improvement in nail psoriasis, as assessed by the Nail Psoriasis Severity Index score, was also observed during treatment with tofacinitib (5 or $10 \mathrm{mg}$ daily) at week 16 and was generally maintained until week $52[3,42,47,53,54]$. Number of adverse events was similar in all four groups [53].

\subsubsection{Adverse Events of Tofacitinib}

The adverse events of tofacitinib included skin infections, skin malignancy and cancers of prostate, lungs, breast and pancreas, lymphomas and lymphoproliferative disorders, infections of respiratory system and urinary tract, activation of latent tuberculosis and reactivation of hepatitis $B$ infection, opportunistic infection, pulmonary cryptococcosis, histoplasmosis, gastrointestinal perforations and obstruction. The laboratory adverse events included decreased hemoglobin levels, RBC, neutrophil and lymphocyte count, and elevation of SGPT, SGOT, CPK, HDL, LDL, TG and cholesterol levels. There was urticaria, angioedema, rash, headache, polyneuropathy and hypertension observed in certain examples [11].

During phase III studies (tofacitinib 5 and $10 \mathrm{mg}$ ), $10-15 \%$ patients with active psoriasis arthritis were observed to have increased lipid levels. These changes were dose-dependent. The highest fluctuations were related to HDL, LDL and total cholesterol [50,55-57]. Hypertriglyceridemia and metabolic syndrome were higher in patients with psoriasis arthritis 
than in patients with rheumatoid arthritis treated by tofacitinib [50,58,59]. Studies showed that tofacitinib does not increase cardiovascular disease risk. Similar results were observed in studies with secuckinumab and ustekinumab [41,50,54,60-63]. During clinical trials estimating the safety of tofacitinib taken 5 or $10 \mathrm{mg}$ twice daily compared with a TNF inhibitor in patients with rheumatoid arthritis, increased risks of pulmonary embolism and mortality in patients who received tofacitinib $10 \mathrm{mg}$ twice daily were noticed $[14,64,65]$. These symptoms were also observed during another independent study that compared tofacitinib with TNF inhibitors [14,66].

During trials PIVOTAL 1 and PIVOTAL 2 in the period to week 16, both doses of tofacitinib were well tolerated. In approximately 900 patients per study, the rates of adverse events were low and similar in all groups of patients. Nausea, headache and diarrhea rates were mildly elevated compared with placebo. There were no opportunistic infections and gastrointestinal perforations. The risk of infection during taking tofacitinib was similar to that of treatments with another biologics $[23,24,42,43,67]$. It was observed that tofacitinib increased the risk of herpes zoster virus infection comparatively to placebo $[14,68]$. Three patients among 363 treated by $5 \mathrm{mg}$ and five patients among 360 patients treated by $10 \mathrm{mg}$ reported herpes zoster in OPT PIVOTAL 1. In OPT PIVOTAL 2, there were three patients among 382 patients treated by $5 \mathrm{mg}$ and one among 381 patients treated by $10 \mathrm{mg}$. All these infections were mild or moderate. Three patients discontinued the study due to herpes zoster events. There was one case of genital herpes in OPT PIVOTAL 1 (10 mg twice daily) and none in OPT PIVOTAL 2. During trials, there were no cases of tuberculosis or other opportunistic infection, no evidence of multidermatomal (more than two dermatomes) or systemic herpes zoster and also no Cytomegalovirus and Epstein-Barr infections [14,42,69].

The most frequent infections were nasopharyngitis, which occurred in OPT PIVOTAL 1 , occurring in $5.5 \%$ of patients treated with $5 \mathrm{mg}$ tofacitinib, $8.6 \%$ patients treated with $10 \mathrm{mg}$ tofacitinib, and $11.3 \%$ with placebo. In OPT PIVOTAL 2 , it occurred in $8.4 \%$ patients treated with $5 \mathrm{mg}$ tofacitinib, 7.9\% patients treated with $10 \mathrm{mg}$ tofacitinib, and 5.6\% with placebo. Quantity of diarrhea (2.2-4.5\%) and headache (4.2-6.9\%) were higher with tofacitinib than placebo $(0-1.7 \%$ and $2.8-3.1 \%$, respectively). Incidence of nausea during taking of tofacitinib was similar to placebo (0.5-2.8\%) [43].

During the first 16 weeks of research, there were four patients with tumors (excluding nonmelanoma skin cancer) in OPT PIVOTAL 1 (malignant melanoma, malignant melanoma, esophageal carcinoma, prostate cancer) and none in OPT PIVOTAL 2. There was one case of basal cell carcinoma and one case of squamous cell carcinoma (10 mg twice daily) in OPT PIVOTAL $2[42,43]$.

In a study with tofacitinib levels of HDL cholesterol, LDL cholesterol and triglycerides were higher during 4 week observations. In the next period (from 4 th to 16 th week), the levels were stable. It was not connected with increases in cardiovascular risk. Major adverse cardiovascular cases were reported in two patients receiving tofacitinib $5 \mathrm{mg}$ twice daily, one receiving $10 \mathrm{mg}$ twice daily and none with placebo; all cases were unrelated to the treatment by tofacitinib [14,43,69].

Higher levels of median cholesterol and creatinine phosphokinase (CPK) and lower levels of median hemoglobin were confirmed with tofacitinib during OPT PIVOTAL 1 and OPT PIVOTAL 2. Seven patients had a CPK level of $>10$ times the upper limit of normal. Among these patients, there were observed moderate myalgia, mild neck pain, and mild arthralgia. No rhabdomyolysis was reported. Mild decreases of blood lymphocyte and hemoglobin were reported in patients with psoriasis healed by tofacitinib; however, these changes decreased and were usually reversible. No severe anemia was confirmed $[14,65,70]$.

\subsection{Baricitinib - General Information and Clinical Trials}

Baricitinib selectively inhibits JAK1/JAK2 tyrosine kinases [71]. Baricitinib has also been tested in clinical double-blind, placebo-controlled, dose-ranging phase $2 \mathrm{~b}$ studies $[4,45]$. 
Before described studies, patients were qualified to be candidates for phototherapy or systemic therapy. Inclusion criteria were: age $\geq 18$ years old, chronic plaque psoriasis for $\geq 6$ months, $\geq 12 \%$ of body surface involved with psoriatic lesions, PASI scores of $\geq 12$ and static Physician's Global Assessment (sPGA) scores of $\geq 3$ on a 6-point scale at study entry. Exclusion criteria were history of serious infections or illnesses, active infections, serious comorbid cardiac or hepatic conditions, immunocompromised states, previous treatment with an oral JAK inhibitor, treatment with a biologic agent or monoclonal antibody within 8 weeks before study, treatment with systemic psoriasis therapy or phototherapy within 4 weeks before study and topical psoriasis therapy within 2 weeks before study.

Patients were randomized to receive placebo or oral baricitinib at 2, 4, 8 or $10 \mathrm{mg}$ once daily for 12 weeks [71]. In this 12-week dose-ranging study, encouraging results in treatment were noticed [13]. The primary end point was Psoriasis Area and Severity Index (PASI) 75\% (PASI-75) at 12 weeks. A 75\% reduction in PASI was achieved by $43 \%$ patients treated with baricitinib $8 \mathrm{mg}$ once daily and $54 \%$ treated with $10 \mathrm{mg}$ versus placebo group (17\%) [7]. Patients achieved significantly higher PASI75 response rates at week 12 compared with placebo. The majority (more than $81 \%$ ) of the respondents maintained their scores through week 24 [45,71].

In conclusion, patients with moderate to severe psoriasis treated with baricitinib for 12 weeks obtained significant improvements in PASI-75 rates versus patients treated with placebo [71].

\section{Adverse Effects of Baricitinib}

There were no serious side effects observed for baricitinib, and this medicine was well tolerated during trial; however, changes in laboratory parameters were similar to those reported for tofacitinib. Baricitinib was observed to cause small dose-related decreases in neutrophil count and hemoglobin levels, as well as small increases in creatinine and lipoprotein levels $[4,14,52,72,73]$. Opportunistic infections were not observed in any treatment group [71].

\subsection{Ruxolitinib-General Information and Clinical Trials}

Ruxolitinib is a JAK1/JAK2 inhibitor that blocks signal transduction of multiple proinflammatory cytokines $[69,72]$. This JAKs inhibitor was used as a topical treatment.

The topical ruxolitinib cream was checked during three psoriasis clinical trials. In a phase 2 vehicle-controlled study in mild and moderate psoriasis, ruxolitinib reported PASI reduction, although no clear dose-response was observed [13].

During the next trial, a double-blind study, ruxolitinib in $1.0 \%$ or $0.5 \%$ cream used once per day or $1.5 \%$ cream twice per day was compared to two active comparators: calcipotriene $0.005 \%$ cream and betamethasone dipropionate $0.05 \%$ cream for 28 days [13,69]. Ruxolitinib achieved clinical efficacy and was non-inferior to active comparators. One percent ruxolitinib cream as well as $1.5 \%$ cream improved erythema, scaling, lesion thickness, erythema and reduced lesion area. It caused their composite lesion score to decrease by more than $50 \%$ compared with $32 \%$ for active comparators $[69,72]$.

Finally, a third study conducted in 25 patients showed that epidermal hyperplasia was reduced with ruxolitinib in most patients [7]. Inclusion criteria in this study were: limited psoriasis (covering $<20 \%$ of the body surface area) and age 18-65 years. Psoriatic lesions were rated on a scale of $0-4$ for erythema, thickness and scaling. Disease activity in each patient was also scored by Physician's Global Assessment scale. The biopsies of pretreatment and posttreatment skin were compared with healthy skin. In these biopsies, histopathology, immunohistochemistry and mRNA expression were evaluated. Laboratory parameters were also measured: ruxolitinib concentrations in plasma, cytokine stimulated phosphorylated signal transducer and activator of transcription 3 phosphorylation (pSTAT3) levels in peripheral blood cells [71]. Topical ruxilitinib phosphate $1.0 \%$ or $1.5 \%$ cream was used once or twice daily for 28 days to $2-20 \%$ body surface area in five sequential groups of patients, each consisting of five patients [69,72]. After application of ruxolitinib phosphate 
cream $1.0 \%$ and $1.5 \%$, there was significant improvement in lesion scores [72]. During the study, these were observed: decreased dermal inflammation, reduction of epidermal hyperplasia, reduction of dermal inflammation, downregulate transcription of Th1 and Th17 cytokines in psoriatic skin lesions and also reduction of CD3, CD11c, Ki67 and keratin 16 observed during immunohistochemical analysis. There were notable interconnections between clinical improvement and decreases in markers of Th17 lymphocyte activation, epidermal hyperplasia and dendritic-cell activation $[4,45,69,72,74]$. However, it was not a sustained improvement after discontinuation [54].

In conclusion of this study, topical ruxolitinib is pharmacologically active in patients with active psoriatic lesions and modulates proinflammatory cytokines $[69,72]$.

\subsection{Adverse Events of Ruxolitinib}

During the double-blind study when ruxolitinib $1.0 \%$ or $0.5 \%$ cream once per day or $1.5 \%$ cream twice per day was compared to two active comparators, inhibition of phosphorylated STAT3 in peripheral blood cells was not observed, suggesting limited systemic exposure $[7,14]$. Systemic absorption was minimal, and there was no evidence of systemic toxicity [75]. Topical ruxolitinib was found to be well tolerated, safe, and efficacious in short-term treatment in a smaller cohort of patients [9].

During topical application in the 25 patients, there was no noticeable inhibition of pSTAT3 in peripheral blood cells observed. It was relevant to be consistent for low steadystate plasma concentrations of ruxolitinib [69,72].

\subsection{Filgotinib - General Information and Clinical Trial}

Filgotinib is an oral selective JAK1 inhibitor. The clinical studies of filgotinib in psoriatic arthritis patients and in other illnesses including rheumatoid arthritis, ankylosing spondylitis and ulcerative colitis are still undergoing and have not been confirmed for selling yet [76].

A randomized, double-blind, placebo-controlled phase II trial (EQUATOR) was conducted in active moderate-to-severe psoriasis arthritis. During these studies, evaluating the efficacy and safety of filgotinib in psoriatic arthritis was assessed [76].

The trial was conducted between 9 March and 27 September 2017. In this study, 191 adult patients from 25 cities in seven countries of Europe (Belgium, Bulgaria, Czech Republic, Estonia, Poland, Spain, and Ukraine) were screened. Of those, 131 patients were randomly divided into treatment regimens: 65 patients for filgotinib in dose $200 \mathrm{mg}$ orally once a day and 66 patients for placebo orally once a day, for 16 weeks [75]. Inclusion criteria were: aged $\geq 18$ years, active moderate-to-severe psoriatic arthritis, documented history or active of plaque psoriasis and an inadequate response or intolerance to at least one conventional synthetic disease-modifying anti-rheumatic drug (csDMARD) [76]. During the study, patients continued to take $\operatorname{csDMAR}=$ if they had received this treatment for at least 12 weeks before screening and had been taking at the same dose for at least 28 days before study [75].

The primary endpoint was proportionate to the patients who achieved $20 \%$ improvement in the American College of Rheumatology response criteria (ACR20) at week 16 [75]. Filgotinib showed better efficacy in the ACR20 and ACR50 rates at week 16 versus placebo. Filgotinib group achieved ACR20 in 80\%, ACR50 in 55\%, LDA (DAPSA $\leq 14$ ) in 49\%, and PASI75 in $45 \%$ of patients. The percentages of the placebo group were respectively 33\%, $12 \%, 15 \%$, and $15 \%[29,76]$. The development in nail psoriasis at week 16 did not achieve statistical significance, probably because of the short study duration and relatively small amount of patients with nail psoriasis $[75,76]$. In total, $92 \%$ patients receiving filgotinib and $97 \%$ patients receiving placebo finished the study [75].

Adverse Events of Filgotinib

During the EQUATOR study, good tolerance of filgotinib was observed. The incidence of adverse events including infections that required treatment was similar in filgotinib 
group versus placebo group at 16 weeks (57\% versus 59\%). Most of adverse events were mild or moderate.

The most frequent adverse events were headache and nasopharyngitis (similar amount in both group of patients). There were no cases of thromboembolic events, malignances or opportunistic infections, and only one case of herpes zoster infection was observed. One serious treatment-emergent adverse event of pneumonia was reported in the filgotinib group. A decrease of platelets, and increases of hemoglobin, HDL and lymphocyte counts were observed in the filgotinib group $[75,76]$.

\subsection{Decernotinib - General Information and Clinical Trial}

Decernotinib is the selective inhibitor of JAK3. In first evaluations, it was shown that it can modulate proinflammatory responses of autoimmune diseases such as rheumatoid arthritis.

During placebo-controlled monotherapy study, decernotinib used in doses 50-150 mg twice per day improved clinical signs of rheumatoid arthritis. Later, during two phase II studies, decernotinib was combined with methotreksat and also improved the symptoms of rheumatoid arthritis compared with placebo $[4,46]$.

\section{Adverse Events of Decernotinib}

Different adverse effects were noticed during these researches: infections-two herpes zoster infections and one case of tuberculosis, neutropenia-in patients in the methotrexate study, increases of liver transaminase, creatin and lipid levels. The metabolite of decernotinib is a potent inhibitor of cytochrome P450, which is involved in metabolism of different drugs. This interaction can complicate the use of decernotinib $[4,46]$.

\section{Conclusions}

The choice of treatment in psoriasis depends on the severity of the disease assessed on the available scales. The assessment considers the extent of the lesions, their locations and severity, the response to previously applied treatment and the impact on the quality of life of patients. Definitions of disease severity are mainly based on the criteria for including patients in randomized controlled trials. Although the classification of disease severity varies, mild psoriasis is generally characterized as a disease that can be treated locally. In moderate or severe psoriasis, an escalation of treatment using phototherapy or a systemic drug can be necessary [77]. From the available treatment options, in the first line are topical steroids, topical vitamin D analogues, retinoids, hydroxyurea and fumaric acid esters. During topical treatment, it is important to use creams with urea, salicylic acid, and cignolin. More advanced external treatment includes UVB or psoralen plus UVA phototherapy. Patients with severe psoriasis can be treated with systemic medications such as methotrexate, cyclosporine and acitretin [78]. Unfortunately, the effectiveness of these drugs is often insufficient and they can cause a variety of side effects. Currently, biologic drugs are an important therapeutic option. The decision to use biologic agents must be carefully considered, based on the clinic and the individual patient risk profile. The type of biologic for psoriasis treatment is chosen according to disease severity and comorbidities. A history of previous biologic treatment and its effectiveness are also important. The main indication for biologic treatment is "moderate-to-severe" psoriasis, but the practicing clinician needs to consider what the exact severity is before qualifying the patient for the treatment. The European Medicines Agency (EMA) guidelines refer to indications such as: failure of topical therapies to control the disease; body surface area (BSA) involvement $>10 \%$ or PASI 10 to 20; thick lesions located in difficult-to-treat regions with BSA involvement $<10 \%$ may also be considered; and category "moderate to severe" on the PGA (Physician's Global Assessment). The NICE recommendations for disease assessment state that both disease severity and impact are relevant and include the use of indexes such as PASI, PGA, patient assessment, enquiry about difficult-to-treat sites, NAPSI (Nails Psoriasis Severity Index), in which nails are the primary indication for systemic therapy, DLQI (Dermatology 
Life Quality Index) and assessment of anxiety and depression $[79,80]$. In addition to the excellent therapeutic effects of biological drugs in psoriasis, there is more talk about the loss of efficacy and its causes. The main cause is the induction of an immune response directed against the foreign protein molecules. Consequently, antibodies directed against the drugs (ADA) are produced. The presence of ADA is associated with lower serum drug levels and loss of clinical efficacy. Furthermore, an increased incidence of ADA-related adverse drug reactions is observed [81]. The development of ADA in psoriasis is still uncertain, but it seems to be similar to the presence of ADA during biologic treatment in other autoimmune diseases such as Crohn's disease and rheumatoid arthritis. Strand et al. [82], in a systematic review based on data from published reports, found that $50 \%$ of patients receiving adalimumab and infliximab developed ADA. Certain factors may influence the immunogenic potential of the agents. These may include the molecular structure of the biologics, concomitant use of methotrexate or other immunosuppressive/anti-proliferative agents, dosage and regimen of the biologic administered and a history of ADA with previous biologic treatment. In addition, patient-related factors may include sex, ethnicity and comorbid conditions [82]. Previous studies indicate well-documented safety and tolerability of biological drugs used in psoriasis. General adverse events (AEs) of biologic treatment are similar. The most frequent $(>10 \%)$ are various infections such as upper and lower respiratory tract infections, rhinitis, sinusitis, pharyngitis and nasopharyngitis. Serious AEs are rare $(<1 \%)$ and may include sepsis, viral reactivation (VZV, HBV, HSV), tuberculosis reactivation and fungal infections. Compared to treatment of psoriasis with non-biologic therapy, biologic therapy has not been significantly associated with major adverse events such as cardiovascular events, malignancy, or death beyond what is anticipated in the overall psoriasis population. Other AEs associated with the liver, including severe hepatic reactions, hepatitis, cholestasis and acute liver dysfunction have been reported. Pancytopenia and aplastic anemia were observed rarely during TNF- $\alpha$ inhibitor treatment. In addition, several cutaneous adverse reactions have been associated with anti-TNF drugs. These include eczematous dermatitis, lupus-like skin reactions, leucocytoclastic vasculitis, lichen planus, lichen-planus-like eruptions and alopecia. The safety profile of anti-IL-12/23 has been reported from the results of large clinical trials, including PHOENIX 1, PHOENIX 2 and ACCEPT. The most common AEs were infections, while $0.7 \%$ of patients had a cardiac disorder and $0.7 \%$ had a serious infection. The most common adverse events that occurred during anti-IL-17A therapy were infections, injection site reactions, nausea and neutropenia [81]. The frequency of adverse effects during therapy with JAK inhibitors is similar to that of other biologic drugs. JAK inhibitors can inhibit the activity of many cytokines that play a role in the pathogenesis of psoriasis. Therefore, JAK inhibition may be associated with an increased risk of infections [83]. Studies to date do not indicate that JAK inhibitors are superior to recent biologic drugs in terms of efficacy. However, the efficacy observed for JAK inhibitors is better than for some currently used systemic therapies, such as some older biologic drugs such as etanercept [15]. JAK inhibitors, due to their lack of increased incidence of side effects compared to other biologic drugs, can be included in the psoriasis treatment algorithm because they are oral and less expensive than modern biologic drugs [15].

The expected results from the clinical trials about JAK inhibitors will be a major step toward extending the therapeutic spectrum of psoriasis by oral compounds. Currently, the number of registered studies on JAK inhibitors in psoriasis is rapidly growing $[9,13]$. The well-established efficacy of JAK inhibitors in inflammatory disorders, particularly rheumatoid arthritis and ulcerative colitis, suggests the potential of their positive effects in a myriad of inflammatory dermatoses as well [8]. More selective JAK inhibitors are currently in clinical trials [9]. Based on the experience with tofacitinib, numerous JAK inhibitors are tested as oral drugs or as topical formulation for psoriasis. Thus far, the efficacy of topical JAK inhibitors for psoriasis is not convincing [13]. Nevertheless, further studies are needed to evaluate long-term treatment effects with these drugs. 
Author Contributions: S.S.-G.-manuscript writing, A.Z.-K.-manuscript writing, K.S.-manuscript writing, A.P.-manuscript writing. All authors have read and agreed to the published version of the manuscript.

Funding: This research received no external funding.

Institutional Review Board Statement: Not applicable.

Informed Consent Statement: Not applicable.

Data Availability Statement: Not applicable.

Conflicts of Interest: The authors declare no conflict of interest.

\section{References}

1. Di Meglio, P.; Villanova, F.; Nestle, F.O. Psoriasis. Cold Spring Harb. Perspect. Med. 2014, 4. [CrossRef]

2. Rapp, S.R.; Feldman, S.R.; Exum, M.L.; Fleischer, A.B., Jr.; Reboussin, D.M. Psoriasis causes as much disability as other major medical diseases. J. Am. Acad. Dermatol. 1999, 41, 401-407. [CrossRef]

3. Sbidian, E.; Chaimani, A.; Garcia-Doval, I.; Do, G.; Hua, C.; Mazaud, C.; Droitcourt, C.; Hughes, C.; Ingram, J.R.; Naldi, L.; et al. Systemic pharmacological treatments for chronic plaque psoriasis: A network meta-analysis. Cochrane Database Syst. Rev. 2017, 12, Cd011535. [CrossRef]

4. Virtanen, A.T.; Haikarainen, T.; Raivola, J.; Silvennoinem, O. Selective JAKinibs: Prospects in Inflammatory and Autoimmune Diseases. BioDrugs 2019, 33, 15. [CrossRef] [PubMed]

5. Gadina, M.; Schwartz, D.M.; O'Shea, J.J. Decernotinib: A Next-Generation Jakinib. Arthritis Rheumatol. 2016, 68, 31-34. [CrossRef]

6. Shuai, K.; Liu, B. Regulation of JAK-STAT signalling in the immune system. Nat. Rev. Immunol. 2003, 3, 900-911. [CrossRef] [PubMed]

7. Howell, M.D.; Kuo, F.I.; Smith, P.A. Targeting the Janus Kinase Family in Autoimmune Skin Diseases. Front. Immunol. 2019, 10, 2342. [CrossRef] [PubMed]

8. Huang, Y.W.; Tsai, T.F. Remission Duration and Long-Term Outcomes in Patients with Moderate-to-Severe Psoriasis Treated by Biologics or Tofacitinib in Controlled Clinical Trials: A 15-Year Single-Center Experience. Dermatol. Ther. 2019, 9, 553-569. [CrossRef]

9. Bechman, K.; Yates, M.; Galloway, J.B. The new entries in the therapeutic armamentarium: The small molecule JAK inhibitors. Pharmacol. Res. 2019, 147, 104392. [CrossRef]

10. Szilveszter, K.P.; Németh, T.; Mócsai, A. Tyrosine Kinases in Autoimmune and Inflammatory Skin Diseases. Front. Immunol. 2019, 10, 1862. [CrossRef]

11. Sonthalia, S.; Aggarwal, P. Oral Tofacitinib: Contemporary Appraisal of Its Role in Dermatology. Indian Dermatol. Online J. 2019, 10, 503-518. [CrossRef]

12. Leonard, W.J.; O'Shea, J.J. Jaks and STATs: Biological implications. Annu. Rev. Immunol. 1998, 16, 293-322. [CrossRef] [PubMed]

13. Solimani, F.; Meier, K.; Ghoreschi, K. Emerging Topical and Systemic JAK Inhibitors in Dermatology. Front. Immunol. 2019, 10, 2847. [CrossRef] [PubMed]

14. Cornejo, M.G.; Boggon, T.J.; Mercher, T. JAK3: A two-faced player in hematological disorders. Int. J. Biochem. Cell Biol. 2009, 41, 2376-2379. [CrossRef]

15. Kvist-Hansen, A.; Hansen, P.R.; Skov, L. Systemic Treatment of Psoriasis with JAK Inhibitors: A Review. Dermatol. Ther. 2020, 10, 29-42. [CrossRef]

16. Wang, H.; Feng, X.; Han, P.; Lei, Y.; Xia, Y.; Tian, D.; Yan, W. The JAK inhibitor tofacitinib ameliorates immune-mediated liver injury in mice. Mol. Med. Rep. 2019, 20, 4883-4892. [CrossRef] [PubMed]

17. Hsu, L.; Armstrong, A.W. JAK inhibitors: Treatment efficacy and safety profile in patients with psoriasis. J. Immunol. Res. 2014, 2014, 283617. [CrossRef]

18. Vainchenker, W.; Constantinescu, S.N. JAK/STAT signaling in hematological malignancies. Oncogene 2013, 32, 2601-2613. [CrossRef] [PubMed]

19. Seavey, M.M.; Dobrzanski, P. The many faces of Janus kinase. Biochem. Pharmacol. 2012, 83, 1136-1145. [CrossRef]

20. He, X.; Chen, X.; Zhang, H.; Xie, T.; Ye, X.Y. Selective Tyk2 inhibitors as potential therapeutic agents: A patent review (2015-2018). Expert Opin. Ther. Pat. 2019, 29, 137-149. [CrossRef]

21. Ghoreschi, K.; Laurence, A.; O'Shea, J.J. Janus kinases in immune cell signaling. Immunol. Rev. 2009, 228, 273-287. [CrossRef]

22. O'Sullivan, L.A.; Liongue, C.; Lewis, R.S.; Stephenson, S.E.; Ward, A.C. Cytokine receptor signaling through the Jak-Stat-Socs pathway in disease. Mol. Immunol. 2007, 44, 2497-2506. [CrossRef]

23. Perner, F.; Schnöder, T.M.; Ranjan, S.; Wolleschak, D.; Ebert, C.; Pils, M.C.; Frey, S.; Polanetzki, A.; Fahldieck, C.; Schönborn, U.; et al. Specificity of JAK-kinase inhibition determines impact on human and murine T-cell function. Leukemia 2016, 30, 991-995. [CrossRef]

24. Schwartz, D.M.; Kanno, Y.; Villarino, A.; Ward, M.; Gadina, M.; O'Shea, J.J. JAK inhibition as a therapeutic strategy for immune and inflammatory diseases. Nat. Rev. Drug Discov. 2017, 17, 78. [CrossRef] [PubMed] 
25. Kim, J.; Tomalin, L.; Lee, J.; Fitz, L.J.; Berstein, G.; Correa-da Rosa, J.; Garcet, S.; Lowes, M.A.; Valdez, H.; Wolk, R.; et al. Reduction of Inflammatory and Cardiovascular Proteins in the Blood of Patients with Psoriasis: Differential Responses between Tofacitinib and Etanercept after 4 Weeks of Treatment. J. Investig. Dermatol. 2018, 138, 273-281. [CrossRef] [PubMed]

26. Singh, S.; Pradhan, D.; Puri, P.; Ramesh, V.; Aggarwal, S.; Nayek, A.; Jain, A.K. Genomic alterations driving psoriasis pathogenesis. Gene 2019, 683, 61-71. [CrossRef] [PubMed]

27. Eder, L.; Wu, Y.; Chandran, V.; Cook, R.; Gladman, D.D. Incidence and predictors for cardiovascular events in patients with psoriatic arthritis. Ann. Rheum. Dis. 2016, 75, 1680-1686. [CrossRef]

28. Sakkas, L.I.; Zafiriou, E.; Bogdanos, D.P. Mini Review: New Treatments in Psoriatic Arthritis. Focus on the IL-23/17 Axis. Front. Pharmacol. 2019, 10, 872. [CrossRef] [PubMed]

29. Elli, E.M.; Baratè, C.; Mendicino, F.; Palandri, F.; Palumbo, G.A. Mechanisms Underlying the Anti-inflammatory and Immunosuppressive Activity of Ruxolitinib. Front. Oncol. 2019, 9, 1186. [CrossRef]

30. US Food and Drug Administration. Xeljanz®Highlights of Prescribing Information. Available online: https://www.accessdata. fda.gov/drugsatfda_docs/label/2018/203214s0181bl.pdf (accessed on 4 December 2018).

31. Purohit, V.S.; Ports, W.C.; Wang, C.; Riley, S. Systemic Tofacitinib Concentrations in Adult Patients With Atopic Dermatitis Treated With 2\% Tofacitinib Ointment and Application to Pediatric Study Planning. J. Clin. Pharmacol. 2019, 59, 811-820. [CrossRef]

32. Xie, R.; Deng, C.; Wang, Q.; Kanik, K.S.; Nicholas, T.; Menon, S. Population pharmacokinetics of tofacitinib in patients with psoriatic arthritis. Int. J. Clin. Pharmacol. Ther. 2019, 57, 464-473. [CrossRef] [PubMed]

33. US Department of Health and Human Services. Clinical Pharmacology and Biopharmaceutics Review(s). Application Number: 203214Orig1s000. 2011. Available online: https://www.accessdata.fda.gov/drugsatfda_docs/nda/2019/206089Orig1s000 ClinPharmR.pdf (accessed on 10 January 2019).

34. Boyle, D.L.; Soma, K.; Hodge, J.; Kavanaugh, A.; Mandel, D.; Mease, P.; Shurmur, R.; Singhal, A.K.; Wei, N.; Rosengren, S.; et al. The JAK inhibitor tofacitinib suppresses synovial JAK1-STAT signalling in rheumatoid arthritis. Ann. Rheum. Dis. 2015, 74, 1311-1316. [CrossRef]

35. Gladman, D.; Rigby, W.; Azevedo, V.F.; Behrens, F.; Blanco, R.; Kaszuba, A.; Kudlacz, E.; Wang, C.; Menon, S.; Hendrikx, T.; et al. Tofacitinib for Psoriatic Arthritis in Patients with an Inadequate Response to TNF Inhibitors. N. Engl. J. Med. 2017, 377, 1525-1536. [CrossRef] [PubMed]

36. Nash, P.; Coates, L.C.; Fleischmann, R.; Papp, K.A.; Gomez-Reino, J.J.; Kanik, K.S.; Wang, C.; Wu, J.; Menon, S.; Hendrikx, T.; et al. Efficacy of Tofacitinib for the Treatment of Psoriatic Arthritis: Pooled Analysis of Two Phase 3 Studies. Rheumatol. Ther. 2018, 5, 567-582. [CrossRef]

37. Pouillon, L.; Bossuyt, P.; Peyrin-Biroulet, L. Tofacitinib Is the Right OCTAVE for Ulcerative Colitis. Gastroenterology 2017, 153, 862-864. [CrossRef] [PubMed]

38. Mease, P.; Hall, S.; FitzGerald, O.; Van der Heijde, D.; Merola, J.F.; Avila-Zapata, F.; Cieślak, D.; Graham, D.; Wang, C.; Menon, S.; et al. Tofacitinib or Adalimumab versus Placebo for Psoriatic Arthritis. N. Engl. J. Med. 2017, 377, 1537-1550. [CrossRef]

39. Ly, K.; Beck, K.M.; Smith, M.P.; Orbai, A.M.; Liao, W. Tofacitinib in the management of active psoriatic arthritis: Patient selection and perspectives. Psoriasis 2019, 9, 97-107. [CrossRef] [PubMed]

40. Dhillon, S. Tofacitinib: A Review in Rheumatoid Arthritis. Drugs 2017, 77, 1987-2001. [CrossRef]

41. Gladman, D.D.; Ang, M.; Su, L.; Tom, B.D.; Schentag, C.T.; Farewell, V.T. Cardiovascular morbidity in psoriatic arthritis. Ann. Rheum. Dis. 2009, 68, 1131-1135. [CrossRef]

42. Wolk, R.; Armstrong, E.J.; Hansen, P.R.; Thiers, B.; Lan, S.; Tallman, A.M.; Kaur, M.; Tatulych, S. Effect of tofacitinib on lipid levels and lipid-related parameters in patients with moderate to severe psoriasis. J. Clin. Lipidol. 2017, 11, 1243-1256. [CrossRef]

43. Krishnaswami, S.; Chow, V.; Boy, M.; Wang, C.; Chan, G. Pharmacokinetics of tofacitinib, a janus kinase inhibitor, in patients with impaired renal function and end-stage renal disease. J. Clin. Pharmacol. 2014, 54, 46-52. [CrossRef] [PubMed]

44. Bayart, C.B.; DeNiro, K.L.; Brichta, L.; Craiglow, B.G.; Sidbury, R. Topical Janus kinase inhibitors for the treatment of pediatric alopecia areata. J. Am. Acad. Dermatol. 2017, 77, 167-170. [CrossRef]

45. Desai, R.J.; Pawar, A.; Weinblatt, M.E.; Kim, S.C. Comparative Risk of Venous Thromboembolism in Rheumatoid Arthritis Patients Receiving Tofacitinib Versus Those Receiving Tumor Necrosis Factor Inhibitors: An Observational Cohort Study. Arthritis Rheumatol. 2019, 71, 892-900. [CrossRef]

46. Westhovens, R. Clinical efficacy of new JAK inhibitors under development. Just more of the same? Rheumatology 2019, 58, i27-i33. [CrossRef] [PubMed]

47. Mahadevan, U.; Dubinsky, M.C.; Su, C.; Lawendy, N.; Jones, T.V.; Marren, A.; Zhang, H.; Graham, D.; Clowse, M.E.B.; Feldman, S.R.; et al. Outcomes of Pregnancies With Maternal/Paternal Exposure in the Tofacitinib Safety Databases for Ulcerative Colitis. Inflamm. Bowel Dis. 2018, 24, 2494-2500. [CrossRef]

48. Fragoulis, G.E.; McInnes, I.B.; Siebert, S. JAK-inhibitors. New players in the field of immune-mediated diseases, beyond rheumatoid arthritis. Rheumatology 2019, 58, i43-i54. [CrossRef] [PubMed]

49. Callis Duffin, K.; Bushmakin, A.G.; Cappelleri, J.C.; Mallbris, L.; Mamolo, C. A multi-item Physician Global Assessment scale to assess psoriasis disease severity: Validation based on four phase III tofacitinib studies. BMC Dermatol. 2019, 19, 8. [CrossRef]

50. Colombel, J.F. Herpes Zoster in Patients Receiving JAK Inhibitors for Ulcerative Colitis: Mechanism, Epidemiology, Management, and Prevention. Inflamm. Bowel Dis. 2018, 24, 2173-2182. [CrossRef] [PubMed] 
51. Winthrop, K.L.; Lebwohl, M.; Cohen, A.D.; Weinberg, J.M.; Tyring, S.K.; Rottinghaus, S.T.; Gupta, P.; Ito, K.; Tan, H.; Kaur, M.; et al. Herpes zoster in psoriasis patients treated with tofacitinib. J. Am. Acad. Dermatol. 2017, 77, 302-309. [CrossRef]

52. Papp, K.; Pariser, D.; Catlin, M.; Wierz, G.; Ball, G.; Akinlade, B.; Zeiher, B.; Krueger, J.G. A phase 2a randomized, double-blind, placebo-controlled, sequential dose-escalation study to evaluate the efficacy and safety of ASP015K, a novel Janus kinase inhibitor, in patients with moderate-to-severe psoriasis. Br. J. Dermatol. 2015, 173, 767-776. [CrossRef]

53. European Medicines Agency. Restrictions in Use of Xeljanz While EMA Reviews Risk of Blood Clots in Lungs. Available online: https: / / regulatory-access.parexel.com/news-and-press-releases/restrictions-in-use-of-xeljanz-while-ema-reviews-riskof-blood-clots-in-lungs-prac-17-05-2019 (accessed on 24 September 2019).

54. Miller, I.M.; Skaaby, T.; Ellervik, C.; Jemec, G.B. Quantifying cardiovascular disease risk factors in patients with psoriasis: A meta-analysis. Br. J. Dermatol. 2013, 169, 1180-1187. [CrossRef] [PubMed]

55. Kitas, G.D.; Gabriel, S.E. Cardiovascular disease in rheumatoid arthritis: State of the art and future perspectives. Ann. Rheum. Dis. 2011, 70, 8-14. [CrossRef] [PubMed]

56. Toms, T.E.; Panoulas, V.F.; Kitas, G.D. Dyslipidaemia in rheumatological autoimmune diseases. Open Cardiovasc. Med. J. 2011, 5 , 64-75. [CrossRef]

57. Hudgins, L.C.; Parker, T.S.; Levine, D.M.; Gordon, B.R.; Saal, S.D.; Jiang, X.C.; Seidman, C.E.; Tremaroli, J.D.; Lai, J.; Rubin, A.L. A single intravenous dose of endotoxin rapidly alters serum lipoproteins and lipid transfer proteins in normal volunteers. J. Lipid Res. 2003, 44, 1489-1498. [CrossRef]

58. Bachelez, H.; Van de Kerkhof, P.C.; Strohal, R.; Kubanov, A.; Valenzuela, F.; Lee, J.H.; Yakusevich, V.; Chimenti, S.; Papacharalambous, J.; Proulx, J.; et al. Tofacitinib versus etanercept or placebo in moderate-to-severe chronic plaque psoriasis: A phase 3 randomised non-inferiority trial. Lancet 2015, 386, 552-561. [CrossRef]

59. Samarasekera, E.J.; Neilson, J.M.; Warren, R.B.; Parnham, J.; Smith, C.H. Incidence of cardiovascular disease in individuals with psoriasis: A systematic review and meta-analysis. J. Investig. Dermatol. 2013, 133, 2340-2346. [CrossRef]

60. Ahlehoff, O.; Gislason, G.H.; Charlot, M.; Jørgensen, C.H.; Lindhardsen, J.; Olesen, J.B.; Abildstrøm, S.Z.; Skov, L.; Torp-Pedersen, C.; Hansen, P.R. Psoriasis is associated with clinically significant cardiovascular risk: A Danish nationwide cohort study. J. Intern. Med. 2011, 270, 147-157. [CrossRef] [PubMed]

61. Juneblad, K.; Rantapää-Dahlqvist, S.; Alenius, G.M. Disease Activity and Increased Risk of Cardiovascular Death among Patients with Psoriatic Arthritis. J. Rheumatol. 2016, 43, 2155-2161. [CrossRef]

62. Labitigan, M.; Bahče-Altuntas, A.; Kremer, J.M.; Reed, G.; Greenberg, J.D.; Jordan, N.; Putterman, C.; Broder, A. Higher rates and clustering of abnormal lipids, obesity, and diabetes mellitus in psoriatic arthritis compared with rheumatoid arthritis. Arthritis Care Res. 2014, 66, 600-607. [CrossRef]

63. Hansson, G.K. Inflammation, atherosclerosis, and coronary artery disease. N. Engl. J. Med. 2005, 352, 1685-1695. [CrossRef]

64. Charles-Schoeman, C.; Gonzalez-Gay, M.A.; Kaplan, I.; Boy, M.; Geier, J.; Luo, Z.; Zuckerman, A.; Riese, R. Effects of tofacitinib and other DMARDs on lipid profiles in rheumatoid arthritis: Implications for the rheumatologist. Semin. Arthritis Rheum. 2016, 46, 71-80. [CrossRef]

65. Wu, J.J.; Strober, B.E.; Hansen, P.R.; Ahlehoff, O.; Egeberg, A.; Qureshi, A.A.; Robertson, D.; Valdez, H.; Tan, H.; Wolk, R. Effects of tofacitinib on cardiovascular risk factors and cardiovascular outcomes based on phase III and long-term extension data in patients with plaque psoriasis. J. Am. Acad. Dermatol. 2016, 75, 897-905. [CrossRef] [PubMed]

66. Charles-Schoeman, C.; Wicker, P.; Gonzalez-Gay, M.A.; Boy, M.; Zuckerman, A.; Soma, K.; Geier, J.; Kwok, K.; Riese, R. Cardiovascular safety findings in patients with rheumatoid arthritis treated with tofacitinib, an oral Janus kinase inhibitor. Semin. Arthritis Rheum. 2016, 46, 261-271. [CrossRef] [PubMed]

67. Ogdie, A.; Yu, Y.; Haynes, K.; Love, T.J.; Maliha, S.; Jiang, Y.; Troxel, A.B.; Hennessy, S.; Kimmel, S.E.; Margolis, D.J.; et al. Risk of major cardiovascular events in patients with psoriatic arthritis, psoriasis and rheumatoid arthritis: A population-based cohort study. Ann. Rheum. Dis. 2015, 74, 326-332. [CrossRef]

68. Savage, L.J.; Wittmann, M.; McGonagle, D.; Helliwell, P.S. Ustekinumab in the Treatment of Psoriasis and Psoriatic Arthritis. Rheumatol. Ther. 2015, 2, 1-16. [CrossRef] [PubMed]

69. Punwani, N.; Burn, T.; Scherle, P.; Flores, R.; Shi, J.; Collier, P.; Hertel, D.; Haley, P.; Lo, Y.; Waeltz, P.; et al. Downmodulation of key inflammatory cell markers with a topical Janus kinase $1 / 2$ inhibitor. Br. J. Dermatol. 2015, 173, 989-997. [CrossRef]

70. US Food and Drug Administration. Safety Trial Finds Risk of Blood Clots in the Lungs and Death with Higher Dose of Tofacitinib (Xeljanz, Xeljanz XR) in Rheumatoid Arthritis Patients; FDA to Investigate. Available online: https://www.fda.gov/drugs/drugsafety-and-availability/safety-trial-finds-risk-blood-clots-lungs-and-death-higher-dose-tofacitinib-xeljanz-xeljanz-xr (accessed on 15 April 2019).

71. Strober, B.; Buonanno, M.; Clark, J.D.; Kawabata, T.; Tan, H.; Wolk, R.; Valdez, H.; Langley, R.G.; Harness, J.; Menter, A.; et al. Effect of tofacitinib, a Janus kinase inhibitor, on haematological parameters during 12 weeks of psoriasis treatment. Br. J. Dermatol. 2013, 169, 992-999. [CrossRef]

72. Papp, K.A.; Menter, M.A.; Raman, M.; Disch, D.; Schlichting, D.E.; Gaich, C.; Macias, W.; Zhang, X.; Janes, J.M. A randomized phase $2 \mathrm{~b}$ trial of baricitinib, an oral Janus kinase (JAK) $1 /$ JAK2 inhibitor, in patients with moderate-to-severe psoriasis. Br. J. Dermatol. 2016, 174, 1266-1276. [CrossRef] 
73. Bissonnette, R.; Luchi, M.; Fidelus-Gort, R.; Jackson, S.; Zhang, H.; Flores, R.; Newton, R.; Scherle, P.; Yeleswaram, S.; Chen, X.; et al. A randomized, double-blind, placebo-controlled, dose-escalation study of the safety and efficacy of INCB039110, an oral janus kinase 1 inhibitor, in patients with stable, chronic plaque psoriasis. J. Dermatol. Treat. 2016, 27, 332-338. [CrossRef]

74. Punwani, N.; Scherle, P.; Flores, R.; Shi, J.; Liang, J.; Yeleswaram, S.; Levy, R.; Williams, W.; Gottlieb, A. Preliminary clinical activity of a topical JAK1/2 inhibitor in the treatment of psoriasis. J. Am. Acad. Dermatol. 2012, 67, 658-664. [CrossRef]

75. Mease, P.; Coates, L.C.; Helliwell, P.S.; Stanislavchuk, M.; Rychlewska-Hanczewska, A.; Dudek, A.; Abi-Saab, W.; Tasset, C.; Meuleners, L.; Harrison, P.; et al. Efficacy and safety of filgotinib, a selective Janus kinase 1 inhibitor, in patients with active psoriatic arthritis (EQUATOR): Results from a randomised, placebo-controlled, phase 2 trial. Lancet 2018, 392, 2367-2377. [CrossRef]

76. Chen, M.; Dai, S.M. A novel treatment for psoriatic arthritis: Janus kinase inhibitors. Chin. Med. J. 2020, 133, 959-967. [CrossRef]

77. Smith, C.H.; Barker, J.N. Psoriasis and its management. BMJ 2006, 333, 380-384. [CrossRef] [PubMed]

78. Golbari, N.M.; Porter, M.L.; Kimball, A.B. Current guidelines for psoriasis treatment: A work in progress. Cutis 2018, 101, 10-12.

79. Abrouk, M.; Nakamura, M.; Zhu, T.H.; Farahnik, B.; Koo, J.; Bhutani, T. The impact of PASI 75 and PASI 90 on quality of life in moderate to severe psoriasis patients. J. Dermatol. Treat. 2017, 28, 488-491. [CrossRef]

80. Smith, C.H.; Yiu, Z.Z.N.; Bale, T.; Burden, A.D.; Coates, L.C.; Edwards, W.; MacMahon, E.; Mahil, S.K.; McGuire, A.; Murphy, R.; et al. British Association of Dermatologists guidelines for biologic therapy for psoriasis 2020: A rapid update. Br. J. Dermatol. 2020, 183, 628-637. [CrossRef] [PubMed]

81. Lockwood, S.J.; Prens, L.M.; Kimball, A.B. Adverse Reactions to Biologics in Psoriasis. Curr. Probl. Dermatol. 2018, 53, 1-14. [CrossRef]

82. Strand, V.; Balsa, A.; Al-Saleh, J.; Barile-Fabris, L.; Horiuchi, T.; Takeuchi, T.; Lula, S.; Hawes, C.; Kola, B.; Marshall, L. Immunogenicity of Biologics in Chronic Inflammatory Diseases: A Systematic Review. BioDrugs 2017, 31, 299-316. [CrossRef] [PubMed]

83. Bechman, K.; Subesinghe, S.; Norton, S.; Atzeni, F.; Galli, M.; Cope, A.P.; Winthrop, K.L.; Galloway, J.B. A systematic review and meta-analysis of infection risk with small molecule JAK inhibitors in rheumatoid arthritis. Rheumatology 2019, 58, 1755-1766. [CrossRef] [PubMed] 